\title{
HEAT TREATMENT OF TUNISIAN SOFT WOOD SPECIES: EFFECT ON THE DURABILITY, CHEMICAL MODIFICATIONS AND MECHANICAL PROPERTIES
}

\author{
M. Elaieb ${ }^{1}$, K. Candelier $^{2}$, A. Pétrissans ${ }^{3}$, S. Dumarçay ${ }^{3}$, \\ P. Gérardin ${ }^{3}$, M. Pétrissans ${ }^{3, \wedge}$
}

\begin{abstract}
Last decades, wood was promoted as building material. Wood heat treatment by mild pyrolysis has been reported to improve biological durability and dimensional stability of the material and constitutes an attractive «non biocidal » alternative to classical preservation treatments. Previous studies have shown that conferred properties strongly depend on the heat treatment intensity. A quality control marker based on mass loss has been developed. For several years, the increased development of Tunisian wood industry provides a significant capacity of wood production and transformation. Forests in Tunisia consist essentially of coniferous species [Aleppo pine (Pinus halepensis), Radiata pine (Pinus radiata), Maritime pine (Pinus pinaster), Stone pine (Pinus pinea)], characterised by a weak natural durability. Improved durability and fungal resistance should allow the use of Tunisian species in the wood industry. Import limitation of European species and the use of local species allow the conservation of economic value added in the country and improve the economic balance. For this reason, several Tunisian softwood species (Aleppo pine, Radiata pine and Maritime pine) have been heat-treated under vacuum atmosphere at $230^{\circ} \mathrm{C}$ to obtain a thermal degradation with mass losses of approximately 8,10 and $12 \%$. The oven device allows recording the dynamic Mass Loss (ML) during the treatment and following the thermodegradation kinetic. The chemical composition of the studied wood samples was determined before and after heat treatment. For each wood species and treatment intensity, wood chemical and mechanical analyses were performed by measuring $\mathrm{O} / \mathrm{C}$ ratio, bending and hardness tests. Afterward, tests of decay resistance were performed according to the EN 113 Standard, with different fungal attacks (Poria Placenta, Coriolus Versicolor) at $22^{\circ} \mathrm{C}$ and $70 \%$ of humidity for 16 weeks. Results were related to the mass loss. Furthermore, intensity of thermal degradation was evaluated by TD-GC-MS. Treated and untreated wood samples were maintained during 15 minutes at $230^{\circ} \mathrm{C}$ under nitrogen in the thermodesorption tube in order to analyse and compare resulting from the wood thermodegradation volatile compounds.
\end{abstract}

Keywords: Chemical analyses, decay resistance, heat treatment, mechanical properties, Tunisian woods, volatile compounds.

\section{INTRODUCTION}

The Wood industry in Tunisia has been working to increase its production. Softwood species dominate in Tunisian forests. Wood is used as industrial wood ( $20 \%$ of the total production), furniture $(10 \%)$, wood for utility service (10\%) and energy applications (60\%). One objective of the industry is to increase the economic valorisation and to improve the national economy. The limited use of wood as a building material is due to the low natural durability of Tunisian woods and leads to low market prices. Producing wood materials with decay resistance and dimensional stability could improve the quality of the local wood. Preservation could be accomplished by thermal modification which is relating simple to implement and environmentally friendly. Heat treatment is an alternative wood preservation method that does not involve additional chemical impregnation, allowing to improves biological durability and dimensional stability (Poncsak et al. 2010), while reducing some mechanical properties (Yildiz et al. 2006).

\footnotetext{
Laboratoire de Gestion et de Valorisation des Ressources Forestières INRGREF, B.P. 10, 2080 Ariana, Tunisia.

CIRAD-Unité de Recherches BioWooEB, TA B 114/16, Montpellier, France.

${ }^{3}$ Laboratoire d'Etudes et de Recherche sur le Matériau Bois, EA 4370, Université de Lorraine, Faculté des Sciences et Technologies, BP 70239, F-54506 Vandœuvre-lès-Nancy, France.

• Corresponding author: Mathieu.Petrissans@univ-lorraine.fr

Received: 30.06.2014 Accepted: 12.04.2015
} 
Heat treatment has been developed in Europe during this last decade leading to industrialisation and commercialization of heat treated timbers. The improved properties of some low natural durability wood species such as pine, spruce, poplar or beech allow their use for outdoor furniture and building materials. The purpose of this study was to test this wood modification process efficiency three Tunisian softwood species (Aleppo pine, Radiata pine and Maritime pine).

\section{EXPERIMENTAL METHODS}

\section{Heat treatment}

Heat treatment was carried out on two wood boards of three species of Tunisian softwoods (IFN, 2005): Aleppo pine (Pinus halepensis), Radiata pine (Pinus radiata), Maritime pine (Pinus pinaster) that were previously dried at $103{ }^{\circ} \mathrm{C}$ till mass stabilization. The boards dimensions were $25 \times 2,5 \times 11$ $\mathrm{cm}^{3}(\mathrm{~L} \times \mathrm{R} \times \mathrm{T})$.

Heat treatment was performed in a 0,25 cubic meter laboratory autoclave by conduction between two electrically heated metallic plates. The device was equipped to record dynamic mass loss as a function of time and temperature (SEIR, Charmes France). Each board, initially dried at $103{ }^{\circ} \mathrm{C}$ for 48 $\mathrm{h}$, was placed in the oven between two metallic plates. The oven was closed and placed under nitrogen or vacuum (200 mbar). The plate temperature was increased at $0,3{ }^{\circ} \mathrm{C} \mathrm{min}^{-1}$ from ambient to drying temperature $\left(103^{\circ} \mathrm{C}\right)$ and held at that temperature until boards mass stabilization. The plate temperature was then increased at $0,3{ }^{\circ} \mathrm{C} \mathrm{min}-1$ from $103{ }^{\circ} \mathrm{C}$ to $170{ }^{\circ} \mathrm{C}$ and maintained for $2 \mathrm{~h}$. Finally temperature was increased by $0,2{ }^{\circ} \mathrm{C} \mathrm{min}{ }^{-1}$ from $170{ }^{\circ} \mathrm{C}$ to $230{ }^{\circ} \mathrm{C}$ to perform the wood thermal treatment until achievement of 8,10 and $12 \%$ mass loss (Figure 1). The wood samples were cooled down to room temperature under inert nitrogen atmosphere. Mass Loss issue from wood thermal degradation seems to be a good parameter to evaluate heat treatment intensity (Pétrissans et al. 2014). For each treatment and each species, decay resistance test, $\mathrm{O} / \mathrm{C}$ ratio determination, bending, hardness and TD-GC-MS analyses have been performed and examined with respect to the mass losses.

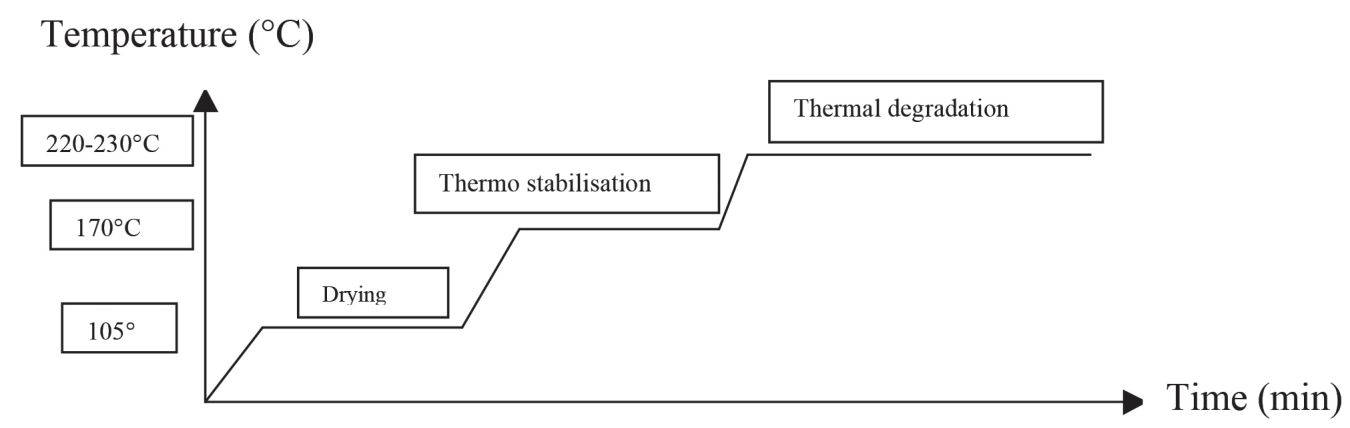

Figure 1. Temperature evolution to achieve thermal treatment.

\section{$\mathrm{O} / \mathrm{C}$ ratio}

For each treatment, $500 \mathrm{mg}$ of wood was ground using a cutting mill Retsch SM 100 and sieved. Particle sizes fraction of 0,2 to $0,5 \mathrm{~mm}$ was retained. Sawdust was conditioned at $103^{\circ} \mathrm{C}$ for $24 \mathrm{~h}$ and stored in closed bottle before analysis. Elemental analyses were performed on a Thermofinnigam Flash EA1112 micro-analyzer equipped with a "Q - Porapak" chromatographic column. The analysis system was managed by the software "Eager 300". Measured elements were carbon, hydrogen and oxygen rates. At least two tests were performed for each sample and all the results are given with an accuracy of $\pm 0,2 \%$. 


\section{Decay resistance}

Decay resistance was assessed according to EN 113/A1 (2004). Blocks [25 x 10 x $5 \mathrm{~mm}^{3}$ (L x R x T)] were cut from heat treated and untreated wood samples, dried at $103^{\circ} \mathrm{C}$ for 48 hours and weighted (m1). Petri dishes $(9 \mathrm{~cm}$ diameter) were filled with sterile culture medium prepared by mixing $30 \mathrm{~g}$ malt and $40 \mathrm{~g}$ agar in $1 \mathrm{~L}$ of distilled water, inoculated with the different fungi and incubated at $22^{\circ} \mathrm{C}$ and $70 \%$ relative humidity to allow full colonization of the surface by the mycelium. Four different fungi were tested: Coriolus versicolor Quélet (CV) [Linnaeus, CTB 863 A], Gloeophyllum trabeum Murill (GT) [Persoon ex Fries, BAM Ebw. 109], Coniophora puteana Karsten (CP) [Schumacher ex Fries, Bam Ebw. 15] and Poria placenta Coocke sensu J. Erikson (PP) [Fries, FPRL 280]. Three blocks ( 2 treated and one untreated as control) were placed in each Petri dish and incubated for 16 weeks at $22^{\circ} \mathrm{C}$ and $70 \%$ relative humidity. Each treatment was tested in triplicate. After incubation, mycelia were scraped from the blocks. Blocks were then dried at $103^{\circ} \mathrm{C}$ and weighed $(\mathrm{m} 2)$ to determine the weight loss caused by the fungal attack.

$$
W L(\%)=100 x \frac{m_{1}-m_{2}}{m_{1}}
$$

\section{Mechanical properties}

The effect of the heat treatment on wood mechanical properties was assessed using three point bending (MOE, MOR) and Brinell hardness tests. An INSTRON 4467 Universal Mechanical Test Machine was used for the measurements. Samples were conditioned to stable weight at $65 \% \mathrm{RH}$ and $22^{\circ} \mathrm{C}$.

Three point static bending tests were carried out according to EN 408 (2003). The samples dimensions were $20 \times 1 \times 1 \mathrm{~cm}^{3}(\mathrm{~L} \times \mathrm{R} \times \mathrm{T})$. The moving head speed and the span length were $1,8 \mathrm{~mm} \cdot \mathrm{s}^{-1}$ and 160 $\mathrm{mm}$, respectively. Load deformation data were analysed to determine the modulus of elasticity (MOE) and the modulus of rupture (MOR). Ten samples were tested for each treatment condition and each wood species. Five samples were used for each heat treated board.

Brinell hardness tests were performed in accordance with EN 408 (2003). The force was applied in three steps by a sphere with a diameter of $10 \mathrm{~mm}$.. Force was slowly increased by $0,2 \mathrm{kN} . \mathrm{s}^{-1}$ over $15 \mathrm{~s}$. Then, a force of $3 \mathrm{kN}$ was maintained for $25 \mathrm{~s}$ before being. Brinell hardness tests were repeated ten times (five tests for each wood board).

Each test was separated by at least $30 \mathrm{~mm}$ from the edge of the wood boards and $25 \mathrm{~mm}$ from any other test. Ball penetration depth was measured to $\pm 0,01 \mathrm{~mm}$ and applied force was measured to $\pm 0,005 \mathrm{kN}$.

\section{TD-GC-MS analyses}

Different heat treated woods and the untreated wood were ground to a powder with particles between 0,2 and $0,5 \mathrm{~mm}$. Approximately $30-40 \mathrm{mg}$ of dried sawdust was placed in a glass thermal desorption tube with $0,8 \mathrm{~cm}$ outer diameter and $9 \mathrm{~cm}$ long (Supelco, Inc.) and end capped with glass wool. Thermal desorption was performed in a Turbomatrix 300 Thermal Desorber system from Perkin Elmer, USA. The conditions included a prepurge for 1 minute at room temperature using helium carrier gas at $1 \mathrm{~mL} \cdot \mathrm{min}^{-1}$ followed by heating at $230{ }^{\circ} \mathrm{C}$ for 15 minutes in the glass thermal desorption tube of the thermodesorber using carrier gas at $20 \mathrm{mLmin}^{-1}$ and split less trapping at $-30{ }^{\circ} \mathrm{C}$. The trap was desorbed at $300{ }^{\circ} \mathrm{C}$ at $1 \mathrm{~mL} \cdot \mathrm{min}^{-1}$ through a transfer line at $300{ }^{\circ} \mathrm{C}$ with a split flow of $40 \mathrm{~mL} \cdot \mathrm{min}^{-1}$. The residual volatile wood degradation products were analyzed by GC-MS after thermodesorption. GC-MS analysis was performed on a Clarus 500 GC - Gas Chromatograph (Perkin-Elmer) equipped with a $5 \%$ diphenyl $/ 95 \%$ dimethyl polysiloxane fused-silica capillary column (J\&W Scientific DB$5,30 \mathrm{~m} \times 0,25 \mathrm{~mm} \times 0,25 \mu \mathrm{m}$ ) and controlled by Turbomass (v5.4.2) software. Ionization was achieved under the electron impact method ( $70 \mathrm{eV}$ ionization energy). The components were identified on the basis of comparison of their mass spectrum with the NIST Library 2005 through the NIST MS Search 2.0. Identification was considered as relevant for the match and reverse match coefficient values above 900. Quantification of degradation products was expressed in peak absolute area unit per mg of sawdust used for TD-GC-MS analysis. Maximum relative standard deviation calculated from 3 replicates for given curing conditions was estimated to $\pm 5 \%$. The TD-GC-MS device was described more preciously in previous studies (Candelier et al. 2011, 2013). 


\section{Statistical analyses}

A statistical analysis of mechanical tests results (one-way analysis of variance) using Fisher test and the JMP 10.0.2 program (SAS Institute Inc., Cary, NC, USA) has been performed. Such analysis allows to class results in four categories from A to D. Systems not connected by the same letter are largely different, at the $5 \%$ level.

\section{RESULTS AND DISCUSSION}

\section{Correlation between $\mathrm{O} / \mathrm{C}$ ratio and intensity level of treatment (ML \%)}

Results revealed that the ratio of oxygen to carbon decreased as the oxygen was removed to the material. Elemental composition was strongly correlated with the heat treatment intensity depending from treatment duration, which directly conditioned the mass losses due to thermal degradation (Figure 2). Previous studies showed similar results (Nguila et al. 2009). For all wood species, O/C ratio decreased linearly with the increase of the mass loss indicating that $\mathrm{O} / \mathrm{C}$ ratio is a good indicator to estimate the mass loss of wood after thermodegradation. This evolution of $\mathrm{O} / \mathrm{C}$ ratio can be attributed to polysaccharide thermal degradation. Hemicelluloses are easily de-acetylated to form acetic acid that catalyzes dehydration and depolymerisation reactions leading to the production of anhydromonosaccharides like furfural (Boonstra et al. 2006, Nguila et al. 2007 and Nguila et al. 2006). O/C ratio decreased when as mass loss due to thermal degradation reactions increased for all wood species. Mass loss was also strongly correlated with $\mathrm{O} / \mathrm{C}$ ratio $\left(\mathrm{R}^{2}>0,9\right)$. Following the recommendation available in the literature (Chaouch et al. 2010), in this study, mass loss is retained as valuable marker of heat treatment intensity.

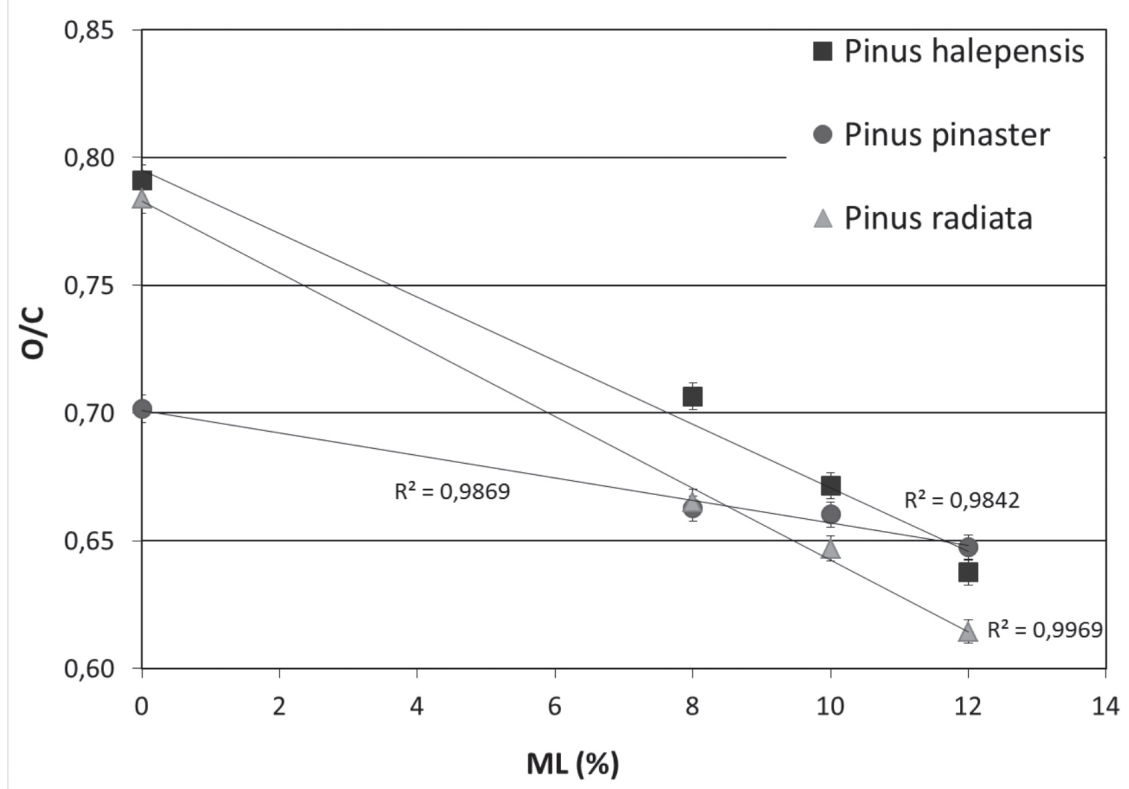

Figure 2. Relationship between $\mathrm{O} / \mathrm{C}$ ratio and thermal Mass Loss (ML) for Pinus halepensis, Pinus pinaster and Pinus radiata, thermally modified to 8,10 or $12 \%$ mass loss. 


\section{Correlation between O/C ratio, decay resistance (WL \%) and mass loss (ML \%)}

Elemental composition and durability against four brown and white rot fungus were measured. For each tested rot, similar results have been found. For this reason and for a better results visibility, following results are focused on the brown rot fungus Poria placenta Coocke sensu J. Erikson (PP) [Fries, FPRL 280]. Poria placenta was the most degrading rot on the different modified wood samples in this study. Correlations between thermodegradation mass losses (ML), fungal weight losses (WL) and carbon content are presented on Figures 3-4. The relationship between the weight losses due to fungal attack and the elemental composition indicated that carbon content and $\mathrm{O} / \mathrm{C}$ ratio could be used to predict the conferred by heat treatment wood durability. Figure 3 shows that the $\mathrm{O} / \mathrm{C}$ ratio was strongly correlated with the weight loss due to fungal degradation $\left(\mathrm{R}^{2}>0,90\right)$. For all wood species, there exists a value of $\mathrm{O} / \mathrm{C}$, which determines the heat treated wood durability. Moreover, it seems that an decreased $\mathrm{O} / \mathrm{C}$ ratio to approximately 0,63 (comparatively to 0,80 for untreated wood) is efficiency to reach a great durability of the treated Tunisian softwood, which corresponds to a used class 3 wood, representing by a weight loss lower than $5 \%$.

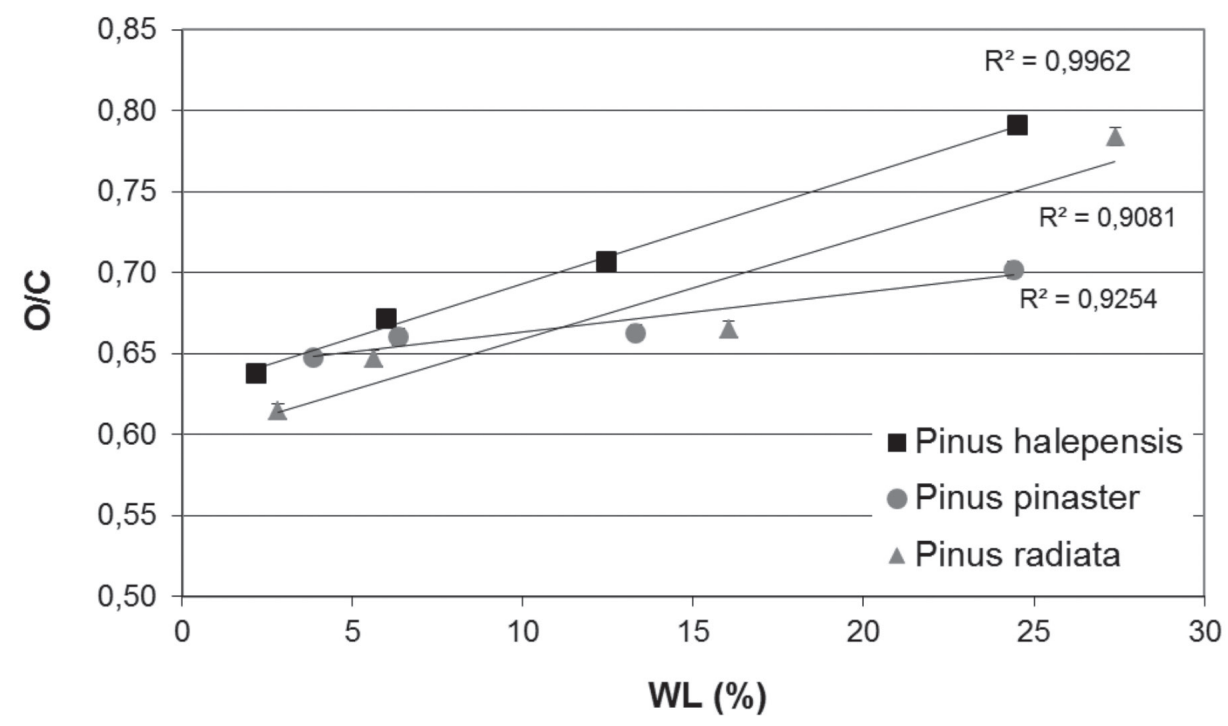

Figure 3. Relationship between $\mathrm{O} / \mathrm{C}$ ratio and weight loss (WL) caused by Poria placenta on three Tunisian softwood species.

A good agreement is achieved with results available in the literature for some European wood species (Chaouch et al. 2010). This last study has shown that $\mathrm{O} / \mathrm{C}$ ratios of approximately 0,52 for softwoods and 0,57 for hardwoods could predict a good decay resistance of heat treated wood.

Figure 4 shows that for all Tunisian softwood species, the weight losses (WL) due to fungal attack were correlated with mass losses resulting from thermal degradation reactions. The durability was almost complete (weight loss is close to $3 \%$ ) when the mass loss reaches $12 \%$ as previously reported by Chaouch et al. 2010, Sustersic et al. 2010, Hakkou et al. 2006 and Welzbacher et al. 2007. 


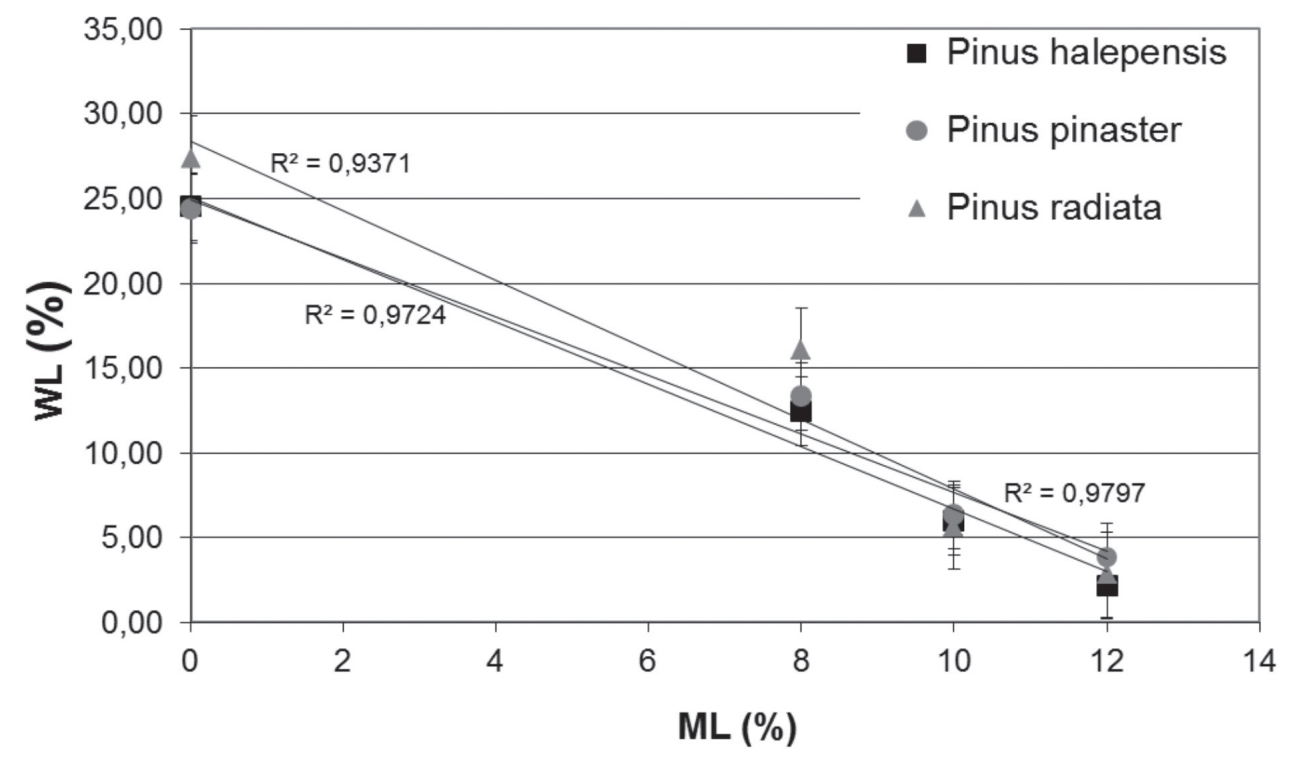

Figure 4. Relationship between fungal Weight Loss (WL) caused by Poria placenta and thermal Mass Loss (ML) and on three Tunisian softwood species.

\section{Mechanical properties}

The mechanical test results of untreated and treated wood samples conditioned at a temperature of $20^{\circ} \mathrm{C}$ and $65 \% \mathrm{RH}$ are shown on figure 5 . Elasticity modulus implies that deformations produced by low stress are recoverable after loads removing. The elasticity modulus (MOE) is commonly used for this test. Modulus of rupture (MOR) reflects the maximum capacity of a member in bending and is proportional to maximum moment borne by a sample. According to the literature, wood strength decreasing depends on wood species, treatment conditions and treatment intensity. An important weakness of heat treated wood concerns mechanical brittleness (Santos 2000, Mouras et al. 2002, Unsal et al. 2005 and Mburu et al. 2008). 

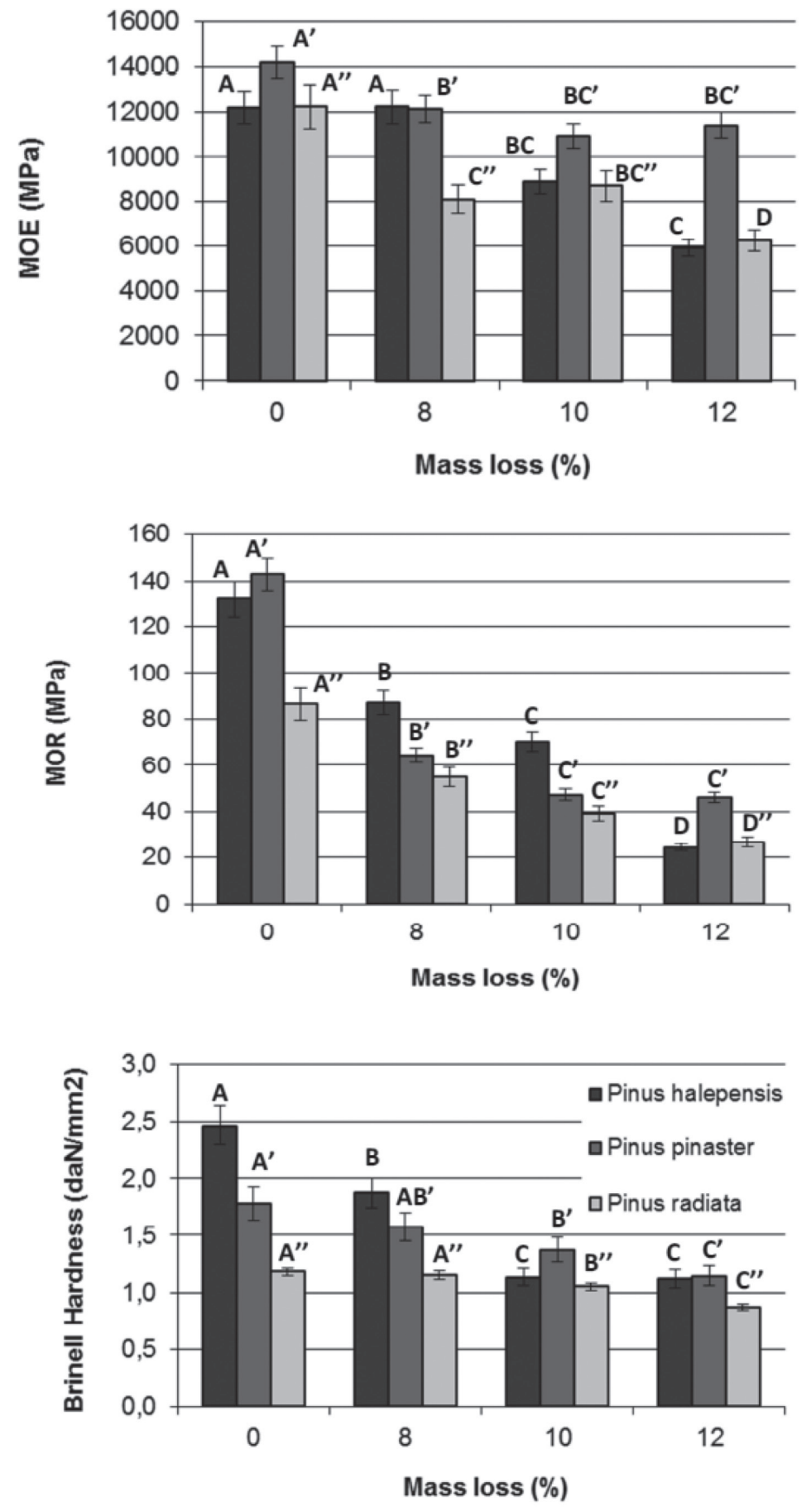

According to one-way analysis of variance, systems not connected by the same letter are largely different, at the $5 \%$ level.

Figure 5. Effect of thermal modification of 3 Tunisian softwood species to 3 target mass losses on bending strength and Brinell hardness. 
Effect of thermal treatment on the mechanical properties is reported on figure 5. Results showed that modulus of rupture (MOR) decreases approximately of 40, 50 and $70 \%$, for each Tunisian wood species treated to respective mass losses of 8,10 and $12 \%$. Modulus of elasticity (MOE) seems to be less degraded after heat treatment. The most important MOE weakening of approximately $50 \%$ is observed on the heat treated Aleppo pine, performed under a treatment intensity leading to a mass loss about $12 \%$. In addition, for each wood species, MOE decreases for treatment intensity corresponding to a mass loss of $8 \%$, while for higher intensity, it seems to be stabilizing. Even if Aleppo pine is the wood species whose the MOE is the most degraded for high treatment level, it seems to be the less sensible softwood to thermal degradation at low treatment intensity compared to Maritime and Radiata pine woods.

There was significant reduction in MOE for heat-treated wood with weight loss of $10 \%$ and more. Reduction in MOE and more particularly MOR progressed with increase in mass loss due to thermal treatment. Previous studies (Yildiz et al. 2006) found that treatment temperature was not the only factor contributing to reduction of MOE. Results confirm that mass loss after thermal treatment seems to be the most important factor influencing the mechanical properties. For all studied, untreated and treated, wood species, the modulus of rupture (MOR) decreases when mass loss due to heat treatment increases. This decrease is mainly due to the depolymerization reactions and changes in the amount of hemicelluloses, which play an important role in strength properties of wood (Hillis 1984, Mburu et al. 2008). Neutral softwood galactomannans and birch glucuronoxylans have been shown to increase fiber to fiber bonding (Otero et al. 2000). Brinell hardness also undergoes a weakening (Korkut 2008) after thermal treatment. Concerning Brinell hardness properties, hardness decreases as a function of the increased treatment intensity (Unsal et al. 2003). Moreover, results show that the most decrease in hardness values were observed between untreated and treated wood with an $8 \%$ mass loss. For higher mass loss, the Brinell hardness is less significantly weakened. And finally for mass loss of 10 and $12 \%$, Brinell hardness is similar, for all heat treated softwood species.

These results have been confirmed by statistical analyses. For each treated wood species, ANOVA analyses highlighted the fact that thermal modification process has a significant effect on the modulus of rupture of the heat treated wood samples with respect to the thermodegradation mass loss (ML), while effects on modulus of elasticity and Brinell hardness are less obvious. Indeed, according to ANOVA analysis, values obtained for MOE and Brinell hardness of samples are not significantly different at 5\% level according to the treatment intensity increase represented by ML.

Thus, heat treatment confers to the new material a good decay resistance. However, the potential of thermally modified Tunisian softwood species in structural applications is reduced. 


\section{Volatile compounds resulting from wood thermal degradation}

In this study, TD-GC-MS has been used to show the difference of remaining extractives in the wood after thermal treatment. Volatile products present in each heat treated samples were analyzed by a classical thermodesorption apparatus coupled to gas chromatography equipped with a mass spectrometer as detector (TD-GC-MS). Thermodesorption was performed at the same temperature than thermal treatment $\left(230^{\circ} \mathrm{C}\right)$ for $15 \mathrm{~min}$ to avoid additional degradation reactions of wood leading to the formation of new by-products while insuring the most complete possible detection. For comparison purposes, untreated sample has also been investigated using the same technique. Chromatograms of thermodesorbed volatile products present in the different treated and untreated Aleppo pine samples are presented in figure 6.
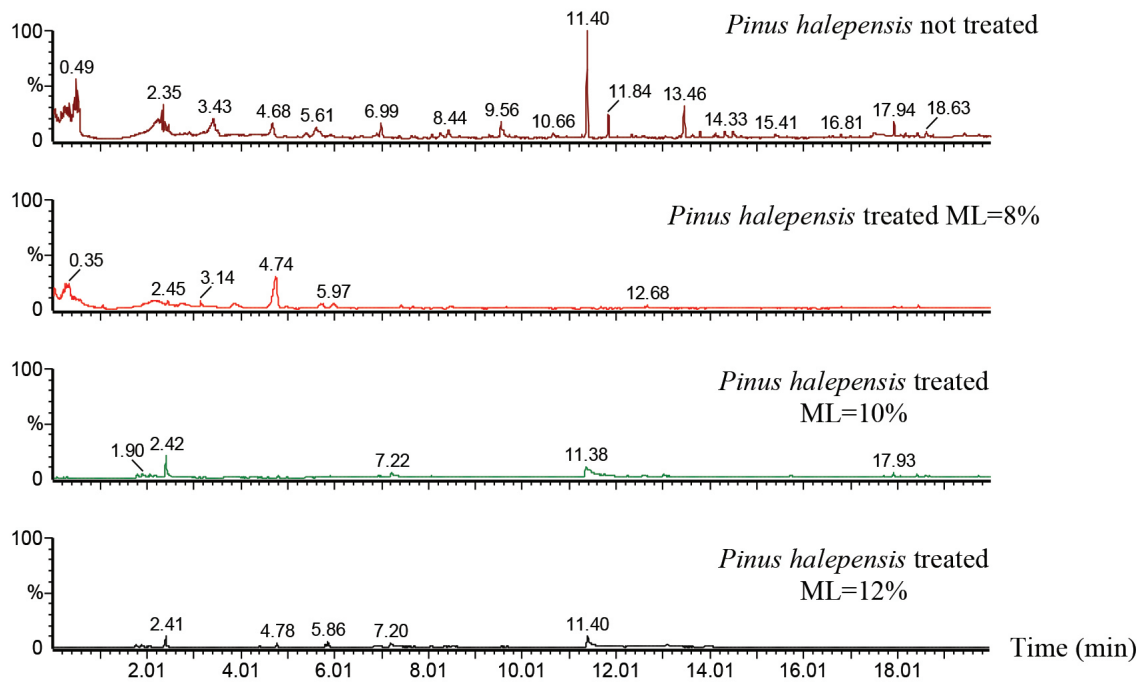

Figure 6. TD-GC-MS analysis showing resulting volatile products in the wood after thermal modification performed on Pinus halepensis according to the 3 target mass losses.

Radiata pine (Pinus radiata), Maritime pine (Pinus pinaster) and Aleppo pine (Pinus halepensis) show a very similar behavior. For this reason, results presented here after concern only the Aleppo pine wood. For the untreated sample, chromatogram (Figure 6) showed several natural extractives, mainly terpenoids, like hexanal (retention time $=3,43$ minutes); beta-pinene $(\mathrm{rt}=4,68)$; camphene $(\mathrm{rt}=4,96)$; nonanal $(\mathrm{rt}=6,99)$; isobornyl acetate $(\mathrm{rt}=8,56)$; caryophyllene $(\mathrm{rt}=11,40)$; humulene $(\mathrm{rt}=11,84)$ and caryophyllene oxide $(\mathrm{rt}=13,46)$ identified as major compounds. Most of these extractives disappeared after thermal treatment. For $8 \%$ mass loss treatment, some monoterpens like pinene $(\mathrm{rt}=4,74)$; terpinyl acetate $(\mathrm{rt}=5,97)$ and natural caproic acid $(\mathrm{rt}=5,71)$ were still detected; a thermal treatment product, the furfural $(\mathrm{rt}=3,85)$ began to appear. For the most severe treatments it can be observed only acetic acid $(\mathrm{rt}=2,42)$ due to hemicelluloses decomposition, and the first lignin degradation products, vanillin $(\mathrm{rt}=11,40)$ and guaiacylacetone $(\mathrm{rt}=13,09)$. Quantitatively, since all these experiments were performed with the same weight of sawdust, it was obvious than the overall amount of extractives was strongly decreased by thermal treatment. TD-GC-MS analyses seems to be a good tool to estimate the wood thermal degradation level and also to predict the industrial conditions of treatment: temperature and duration (by extrapolation). 


\section{CONCLUSIONS}

Effect of heat treatment on the conferred durability, dimensional stability and mechanical properties of three Tunisian softwood species has been studied. TD-GC-MS analyses show that heat treated Tunisian softwood species contain less residual volatile products from hemicelluloses and lignin degradation like acetic acid or vanillin. The quantification of these last residual volatile products could be a good parameter to evaluate the level of wood degradation and to determine the temperature level and the duration treatment. It is also necessary to modify the industrial conditions of heat treatment used for the European species for the Tunisian species. The difference of thermal degradation kinetic is also confirmed by elemental analyses. A good correlation is observed between $\mathrm{O} / \mathrm{C}$ ratio, mass loss due to thermo degradation and conferred decay resistance for the studied Tunisian softwood species. An almost complete durability is achieved when thermodegradation mass loss reaches $12 \%$. Mechanical properties of wood reduce after thermal treatment. MOE decreased insignificantly for all wood species samples having weight loss of less than $10 \%$ above which the decrease is more significant. MOR decreases dramatically starting from a mass loss due to thermo degradation of $8 \%$. Brinell hardness is also affected by thermal treatment. Mass loses is directly connected to heat treatment intensity and seems to be the most important parameter to evaluate the analyzed in this study final mechanical properties of the heat treated wood. This study shows that the improved properties of the heat treated Tunisian softwood make possible the application for outdoor conditions. But this study equally shows that it's necessary to modify the European industrial conditions of treatment to reach upper thermal treatment intensity.

\section{ACKNOWLEDGEMENTS}

The authors gratefully acknowledge the financial support of the CPER 2007-2013 "Structuration du Pôle de Compétitivité Fibres Grand'Est”.

The LERMAB is supported by a grant overseen by the French National Research Agency (ANR) as part of the "Investissements d'Avenir" program (ANR-11-LABX-0002-01, Lab of Excellence ARBRE). 


\section{REFERENCES}

Boonstra, MJ.; Tjeerdsma, B. 2006. Chemical analysis of heat treated softwoods. Holz als Roh und Werkst 64: 204-11.

Candelier, K.; Chaouch, M.; Dumarçay, S.; Pétrissans, A.; Pétrissans, M.; Gérardin, P. 2011. Utilization of thermodesorption coupled to GC-MS to study stability of different wood species to thermodegradation. Journal of Analytical and Applied Pyrolysis 92: 376-383.

Candelier, K.; Dumarçay, S.; Pétrissans, A.; Pétrissans, M.; Kamdem, P.; Gérardin, P. 2013. Thermodesorption coupled to GC-MS to characterize volatiles formation kinetic during wood thermodegradation. Journal of Analytical and Applied Pyrolysis 101: 96-102.

Chaouch, M.; Pétrissans, M.; Pétrissans, A.; Gérardin, P. 2010. Use of wood elemental composition to predict heat treatment intensity and decay resistance of different softwood and hardwood species. Polymer Degradation and Stability 95 : 2255-2259.

EN 113/A1 Standard. 2004. Produits de préservation du bois - Méthode d'essai pour déterminer l'efficacité protectrice vis-à-vis des champignons basidiomycètes lignivores - Détermination du seuil d'efficacité.

EN 408 Standard. 2003. Structures en bois - Bois de structure et bois lamellé-collé. Détermination de certaines propriétés physiques et mécaniques.

Hakkou, M.; Pétrissans, M.; Gérardin, P.; Zoulalian, A. 2006. Investigations of the reasons for fungal durability of heat-treated beech wood. Polym Degrad Stab 9: 393-397.

Hillis, W.E. 1984. High temperature and chemical effects on wood stability. Wood Science and Technology $18: 281-293$.

IFN. 2005. Deuxième Inventaire Forestier et Pastoral National tunisien.

Korkut, S. 2008. The effects of heat treatment on some technological properties in Uludağ fir (Abies bornmuellerinana Mattf.) wood. Building and Environment 43: 422-428.

Mburu, F.; Dumarçay, S.; Bocquet, J.F.; Pétrissans, M.; Gérardin, P. 2008. Effect of chemical modifications caused by heat treatment on mechanical properties of Grevillearobusta wood. Polymer Degradation and Stability 93: 401-405.

Mouras, S.; Girard, P.; Rousset, P.; Permadi, P.; Dirol, D.; Labat, G. 2002. Propriétés physiques de bois peu durables soumis à un traitement de pyrolyse ménagée. Annals of Forest Science 59: 317-26.

Nguila-Inari, G.; Pétrissans, M.; Lambert, J.; Ehrhardt, J.J.; Gérardin, P. 2006. XPS characterization of wood chemical composition after heat treatment. Surf Interface Anal 38: 1336-1342.

Nguila-Inari, G.; Mounguengui, S.; Dumarcxay, S.; Pétrissans, M.; Gérardin, P. 2007. Evidence of char formation during heat treatment by pyrolysis. PolymDegrad Stab 92: 997-1002.

Nguila-Inari, G.; Pétrissans, M.; Pétrissans, A.; Gérardin, P. 2009. Elemental composition of wood as a potential marker to evaluate heat treatment intensity. Polym Degrad Stabil 94: 365-368.

Otero, D.; Sundberg, K.; Holmbom, B.; Blanco, A.; Negro, C.; Tijero, J. 2000. Effects of wood polysaccharides on the depositability of wood resin. Nordic Pulp and Paper Research Journal 15: 607-613. 
Pétrissans, A.; Younsi, R.; Chaouch, M.; Gérardin, P.; Pétrissans, M. 2014. Wood thermodegradation: experimental analysis and modeling of mass loss kinetics. Maderas. Ciencia y Tecnología 16 (2): 133-148.

Poncsak, S.; Kocaefe, D.; Younsi, R. 2010. Improvement of heat treatment of Jack pine (Pinusbanksiana) using Thermowood technology. European Journal of Wood and Woods Products 69 (2): 281-286.

Santos, J.A. 2000. Mechanical behaviour of eucalyptus wood modified by heat. Wood Science and Technology 34: 39-43.

Sustersic, Z.; Mohareb, A.; Chaouch, M.; Pétrissans, M.; Petric, M.; Gérardin, P. 2010. Prediction of decay resistance of heat treated wood on the basis of its elemental composition. Polymer Degradation and Stability 95: 94-97.

Unsal, O.; Korkut, S.; Atik, C. 2003. The effect of heat treatment on some properties and colour in eucalyptus (Eucalyptus camaldulensis Dehn.) wood. Maderas. Ciencia y Tecnología 5 (2): 145-152.

Unsal, O.; Ayrilmis, N. 2005. Variations in compression strength and surface roughness of heat treated Turkish river gum (Eucalyptus camaldulensis) wood. Journal of Wood Science 51: 405-409.

Welzbacher, C.R.; Brischke, C.; Rapp, A.O. 2007. Influence of treatment temperature and duration on selected biological, mechanical, physical and optical properties of thermally modified timber. Wood Material Sci Eng 2: 66-76.

Yildiz, S.; Gezer, E.D.; Yilditz, U.C. 2006. Mechanical and chemical behaviour of spruce wood modified by heat. Building and Environment 41: 1762-1766. 